\title{
Real-Time Lime Quality Control through Process Automation
}

\author{
Vipul Kumar Tiwari, Abhishek Choudhary, Umesh Kr. Singh, Anil Kumar Kothari, Manish Kr. Singh
}

Abstract: In the steel industry - Tata steel, India, most of the lime produced in the lime plant is used in the steel-making process at $L D$ shops. The quality of steel produced at $L D$ shops depends on the quality of lime used. Moreover, the lime also helps in the crucial dephosphorization process during steel-making. The calcined lime produced in the lime plant goes to the laboratory for testing its final quality (CaO\%), which is very difficult to control. To predict, control and enhance the quality of lime during lime making process, five machine-learning-based models such as multivariate linear regression, support vector machine, decision tree, random forest and extreme gradient boosting have been developed using different algorithms. Python has been used as a tool to integrate the algorithms in the models. Each model has been trained on the past 14 months' data of process parameters, collected from level 1 sensor devices, to predict the future quality of lime. To boost the model's prediction performance, hyper-parameter tuning has been performed using grid-search algorithm. A comparative study has been done among all the models to select a final model with the least root mean square error in predicting and control future lime quality. After the comparison, results show that the model incorporating support vector machine algorithm has least value of root mean square error of 1.23 in predicting future lime quality. In addition to this, a self-learning approach has also been incorporated into support vector machine model to enhance its performance further in realtime. The result shows that the performance has been boosted from $85 \%$ strike-rate in +/-2 error range to $90 \%$ of strike-rate in $+/-1$ error range in real-time. Further, the above predictive model has been extended to build a control model which gives prescriptions as output to control the future quality of lime. For this purpose, a golden batch of good data has been fetched which has shown the best quality of lime ( $\geq 94 \%$ of $\mathrm{CaO} \%)$. A good range of process parameters has been extracted in the form of upper control limit and lower control limit to tune the set-points and to give the prescriptions to the user. The integration of these two models (Predictive model and control model) helps in controlling the quality of lime 12 hours before its final production of lime in lime plant. Results show that both models (Predictive model and control model) have $90 \%$ of strike-rate within $+/-1$ of error in real-time. Finally, a human machine interface has been developed to facilitate the user to take action based on control model's output. Eventually this work is deployed as a lime making process automation to predict and control the lime quality.

Keywords: Steel-Making, Quality Control, Process Automation, Machine-Learning, Human-Machine-Interface.

Manuscript received on May 03, 2021.

Revised Manuscript received on May 08, 2021.

Manuscript published on May 30, 2021.

* Correspondence Author

Vipul Kumar Tiwari*, Technologist, Automation Division, Tata Steel, Jamshedpur, 831001, India. E-mail: vipul.tiwari1@tatasteel.com

Abhishek Choudhary, Sr. Manager, Lime plant, Tata Steel, Jamshedpur, 831001, India. E-mail: abhishek.c@ tatasteel.com

Umesh Kr. Singh, Principal Technologist, Automation Division, Tata Steel, Jamshedpur, 831001, India. E-mail: umesh.singh1@tatasteel.com

Anil Kumar Kothari, Chief (SM\&C), Automation Division, Tata Steel, Jamshedpur, 831001, India. E-mail: anil.kothari@tatasteel.com

Manish Kr. Singh, Chief (One IT), Automation Division, Tata Steel, Jamshedpur, 831001, India. E-mail: manishk.singh@tatasteel.com

(c) The Authors. Published by Blue Eyes Intelligence Engineering and Sciences Publication (BEIESP). This is an open access article under the CC BY-NC-ND license (http://creativecommons.org/licenses/by-nc-nd/4.0/)

\section{INTRODUCTION}

The world production of lime is estimated around 350 million tons and $40-45 \%$ of lime is used in steel manufacturing industry globally [1]. Lime as a basic flux plays an important role in the mechanism of metallurgical reactions in steel-making processes [2]. Addition of lime in steelmaking, as shown in Fig. 1, controls the removal of sulphur, which is an unwanted impurity [3]. It is also a critical additive used to form a quality sinter, which is used in ironmaking process [4]. Eventually, lime quality has a significant impact on steel quality, its metallurgical properties, productivity and total cost of production [1].

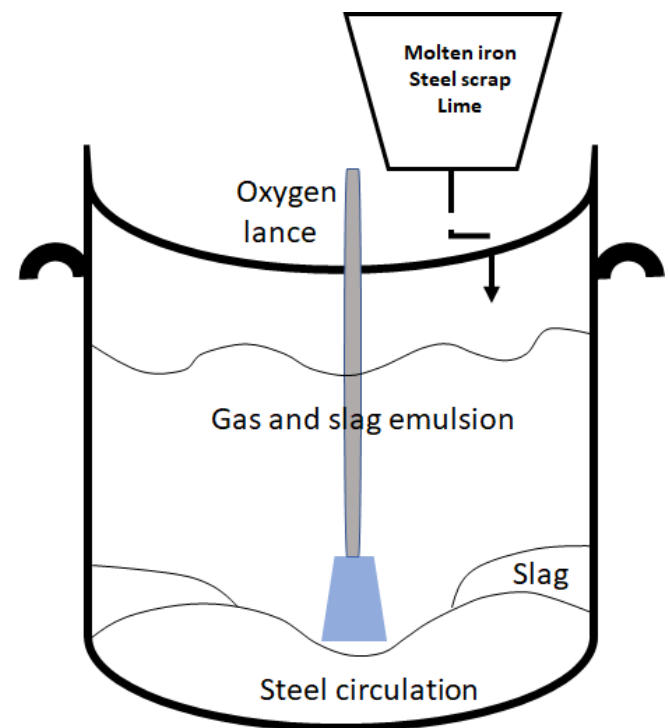

Fig. 1. Lime used in the steel making process.

In lime plant of Tata Steel, this crucial flux lime $(\mathrm{CaO})$, an oxide of calcium, is produced from the limestone (Ca$\mathrm{CO}_{3}$ ) in the presence of a heating agent through below calcination reaction as shown in (1).

$$
\mathrm{CaCO} 3 \stackrel{\text { heat }}{\longrightarrow} \mathrm{CaO}+\mathrm{CO} 2
$$

To complete the above thermal decomposition of limestone into lime, the stones must be heated to the dissociation temperature of the carbonates [5]. The above reaction occurs in a Merz-kiln shaft which takes limestone along with combustion gases as input and produces lime as a product (see Fig. 2).

Published By:

Blue Eyes Intelligence Engineering and Sciences Publication 
This whole process takes 24 hours of time to produce final product of lime (see Fig.2). The lime with some impurities like Si, Fe, P, S, Mn, Al [6] that exit at the kiln outlet is known as quicklime [5]. Then quicklime lime goes to the laboratory (Lab) for quality testing. The $\mathrm{CaO}$ content, which refers to the lime quality plays an important role to make it qualify for steel-making. The quality of lime gets effected by various complex process parameters such as heat-input, combustion gas flow, kiln pressure, kiln temperature etc which are difficult to control. Nevertheless, the development of industry4.0 has made the processes capable of controlling kiln operation considering improvement in the lime quality $(\mathrm{CaO} \%)$ [7]. Moreover, the implementation of automation system as a result of industry4.0 is controlling the production processes through digital technology [8]. Eventually, it results into generation of plethora of data related to various process parameters and output of the lime-production in Merz-kiln. On the other hand, the machines in industry have become smarter than ever before using the big data and artificial intelligence (AI) techniques [9]. The main driver that triggers this innovation is a sub-branch of AI i.e. machine learning (ML). This led the researchers to study the control of plant-processes through the field of data science and machine learning. Although the machine learning field in the view of lime production process is almost unexplored. A research has been presented on overview of available machine learning techniques in manufacturing area [10]. A study for prediction of phosphorus has been performed using industrial data through machine learning approach [11]. The study has compared the different algorithms such as artificial neural network and multivariate regression. A study done by D. S. Vinoo [12] has used multiple linear regression approach to predict the desulphurization reagent during steel-making. It further optimized the prediction of reagent during desulphurization. In another study, advance analytics and deep learning techniques have been presented with application to smart manufacturing [13]. A convolution neural network approach has been adopted to predict the bearing fault in a study presented by Waziralilah [14] et al. A data-driven technique based on deep belief network has been investigated to predict the material removal rate [15]. A data analytics based predictive model has been developed to predict power consumption in manufacturing [16]. Another study based on artificial neural network has been highlighted in lime kiln operation to predict paper quality [17]. A support vector machine based machine learning model has been developed [18]. This study incorporated a PSO algorithm to predict calcined zone temperature in lime kiln [18]. Although various research studies have been presented on data-driven machine learning techniques in manufacturing industries. But, very limited research works are present that shows machine learning approach to explore lime calcination process. Nevertheless, almost no study is available for lime quality control using data-driven machine learning approach.

Currently in lime plant at Tata Steel, lime produced at the end goes to the laboratory (Lab) for testing its quality. This testing process takes additional 24 hrs to know the quality of lime, which creates a lag in controlling the future lime quality during the process. This study aims to predict the lime quality $(\mathrm{CaO} \%)$ on hourly basis at the very end of lime-production cycle (at $16^{\text {th }}$ hour from starting) using plant data-inputs as shown in Fig. 2(a). To solve the purpose, five machine-learning-based models using multivari- ate linear regression (MLR), support vector machine (SVM), decision tree, random forest and extreme gradient boosting (XGBoost) have been developed respectively. A comparative study before validation (statistical and experimental) has been performed to choose the final model based on root mean square error (RMSE) within an acceptable limit. Further, to boost the accuracy of the selected model, parameter tuning has been done by incorporating the grid-search algorithm. Moreover, a self-learning approach has been integrated with the selected model to enhance its performance in real-time.

The above final predictive model has been further extended to develop a control model, as shown in Fig. 2(b), to solve the aim of this study ultimately. The control model gives the prescription to the user for controlling the future lime quality by taking actions in the present.

It gives user a facility to take actions on process parameter at 12th hours in advance before the final production of lime. The current model automatically takes the data from the level 2 automation system (data-base system), predicts lime quality and prescribes the operator to take actions to control the quality on hourly basis. Both predictive and control models have been validated quantitively respectively with plant data. The results show that both models have accuracies of $90 \%$ for the error range in \pm 1 after incorporating the self-learning approach, which met the user demand.

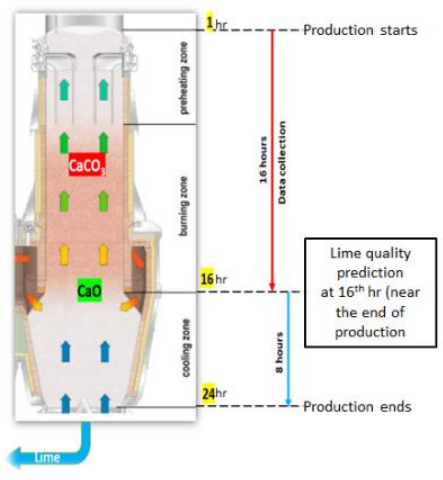

(a)

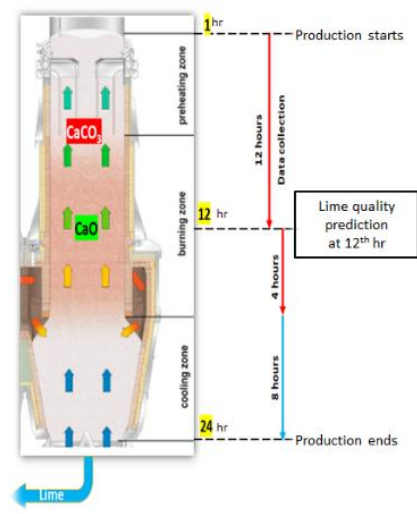

(b)

Fig. 2. Lime Merz-kiln shafts representation with (a) predictive model and (b) control model prediction points.

Published By:

Blue Eyes Intelligence Engineering and Sciences Publication

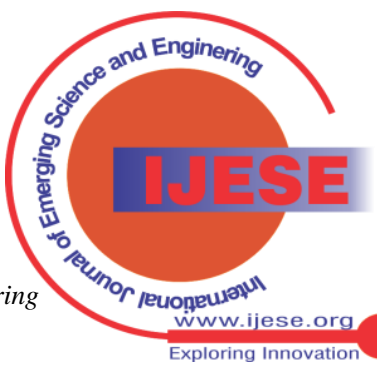




\section{METHODOLOGY}

\section{A. Model Flow Diagram}

Flow diagram for the models-development consists of the step-wise processing to build them as shown in Fig. 3. It includes the steps from data collection to the final model selection followed by results. The models have been developed after cleaning of data collected from the lime plant. Models improvement phase consists of hyper-parameter tuning and self-learning algorithm to boost the all models' performance. All the steps have been elaborated in the subsequent sections.

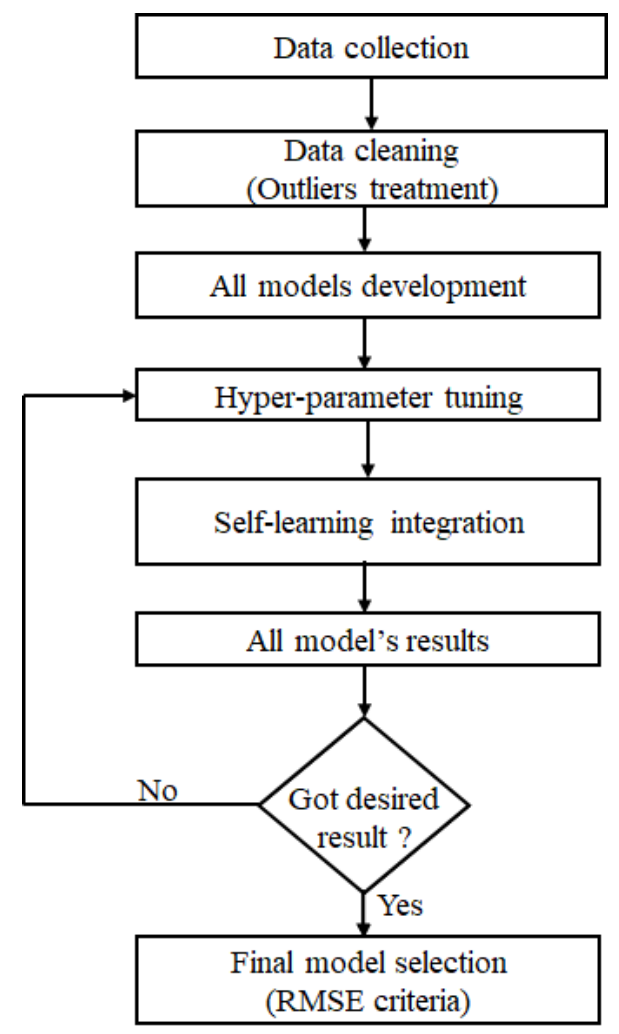

Fig. 3. Model flow diagram.

\section{B. Data Collection and Model Input}

The process parameter's data has been collected from the sensors of lime production plant at Tata Steel. Using crosscorrelation technique and brainstorming with users the final list of data as input $(\mathrm{X})$ and output $(\mathrm{Y})$ has been decided as listed in Table I. The input - output data of 14 months is fetched from level 2 automation system of lime plant. Since there is a time lag of 24 hours between input data and output data $(\mathrm{CaO} \%)$, time synchronization has been done to map the time-scale of input $(\mathrm{X})$ and output $(\mathrm{Y})$ data.

Table-I: List of bin name used in this study

\begin{tabular}{|c|c|}
\hline Independent variables (X) & $\begin{array}{r}\text { Dependent } \\
\text { variable (Y) }\end{array}$ \\
\cline { 1 - 1 } Heat Input & \\
\cline { 1 - 1 } Gas flow & \multirow{2}{*}{ CaO\% } \\
(lime quality)
\end{tabular}

Retrieval Number: 100.1/ijese.B2502057221

DOI: 10.35940/ijese.B2502.057221

Journal Website: www.ijese.org

\begin{tabular}{|c|}
\hline Gas pressure \\
\hline $\begin{array}{c}\text { Kiln pressure } \\
\text { Combustion air pressure }\end{array}$ \\
\hline
\end{tabular}

\section{Data Cleaning}

Data cleaning is the most crucial part in the data science based model development. The data used in the development phase should be authentic and totally free from any undesired values. In the view of the same, we used Python as a tool to clean the data. Missing data has been handled using multiple imputation technique by filling the data with mean value.

The undesired outliers negatively affect the model's output. Treatment of outlier data is based on the $\mathrm{Z}$ score of the respective data points. Only those data points have been considered in the model development which have $\mathrm{Z}$ value less than or equal to 3 . The parameter $Z$ score has been calculated by using a mathematical formula as shown in (2).

$$
Z \text { score }=\frac{X-\bar{X}}{\sigma}
$$

Here, $\bar{X}$ and $\sigma$ represent mean value and standard deviation of data set respectively. $X$ is the value of each data points.

\section{Assumptions: checking for multiple collinearity}

It is assumed that there is no multiple collinearity among input variables (predictors) collected from the plant. Multiple collinearity refers to the presence of any correlation among input variables considered in the model development. The correlation has been represented in the heat map as shown in Fig. 4. It shows that there is high correlation among "Kiln pressure" (KILN_PRES), "Cooling air pressure" (AIR_PRES_COOL), "Combustion air pressure" (AIR_PRES_COMB). This undesired multiple collinearity has been removed from the data using threshold value of 0.9. As a result, "Kiln pressure" and "cooling air pressure" have been removed from the input data set.

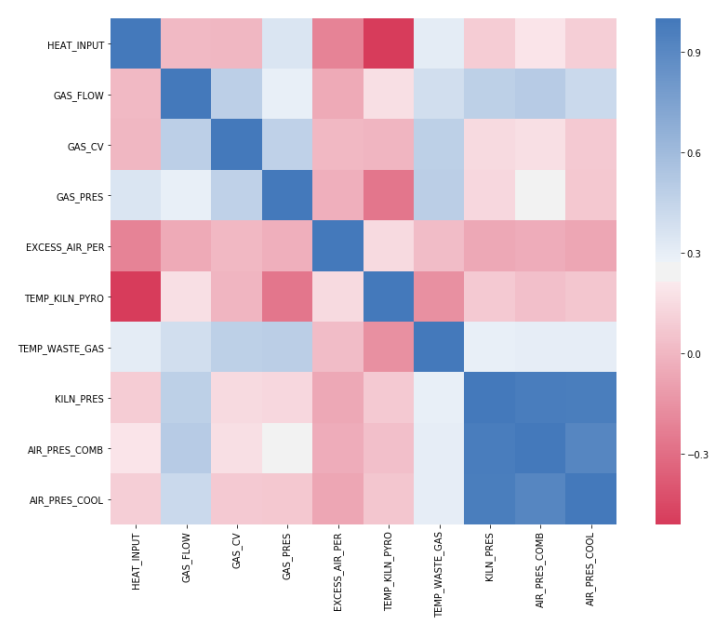

Fig. 4. Cross-correlation matrix for input variables.

Published By:

Blue Eyes Intelligence Engineering 


\section{MODEL DEVELOPMENT}

Python as a tool has been used to develop the model for this work. In this study, following five predictive models have been developed and the best model has been chosen based on root mean square error (RSME).

\section{A. Multivariate Linear Regression}

Multivariate linear regression is one of the basic technique which gives the relationship between features (independent variables) and predicted variable (dependent parameter).

Equation (4) shows mathematical expression for simple linear regression where only two independent variables are present but in multiple linear regression there are more than two independent variables as shown in (5) [19].

$$
Y=A X+B
$$

$$
Y_{i}=\beta_{0}+\beta_{1} X_{i_{1}}+\beta_{2} X_{i_{2}} \ldots \ldots \ldots \ldots+\beta_{n} X_{i_{n}}
$$

Here, $Y=$ Dependent parameter (Output), $X=$ Independent parameter (Input) and $A, B$ and $\beta$ are regression parameters.

\section{B. Support Vector Machine}

The basic concept behind support vector machine (SVM) is to map the original data $X$ into feature space as function $F(X)$ with higher dimensionality through a non-linear mapping function and construct an optimal hyperplane in a new space [20]. This non-linear function $F(X)$ is defined such that it minimizes the loss function $l_{\varepsilon}$ as shown in (6) and (7) respectively [21].

$$
F(X)=\sum_{i=1}^{N}\left(\alpha_{i}^{*}-\alpha_{i}\right) K\left(X, X_{i}\right)+B
$$

Here, $\left(\alpha_{i}^{*}, \alpha_{i}>0\right), B, K$ are Lagrange multipliers, bias term and kernel function respectively [20]. $X, X_{i}$ are the independent variable's data points.

$$
\begin{aligned}
& l_{\varepsilon}\left(y_{i}-F\left(X_{i}\right)\right)=0 \text { for }\left|y_{i}-F\left(X_{i}\right)\right|<\varepsilon \\
= & \left|y_{i}-F\left(X_{i}\right)\right| \text { for other cases }
\end{aligned}
$$

Here, $\mathrm{y}_{\mathrm{i}}$ is target (dependent) variables and $\varepsilon$ is the difference between target and predicted values [21].

Support vector machines finds a hyperplane with maximum margin from support vectors which divides the data set into two classes. Support vectors are the data points which are closest to the hyperplane as shown in Fig. 5. The kernel $\mathrm{K}$ has been used to transform the data into non-linear hyperplane. In this study, a radial base function as shown in (8) as gaussian kernel has been used for the transformation of dataset into non-linear space [21].

$$
K\left(X, X_{i}\right)=e^{\left(-\left\|X-X_{i}\right\|^{2} / 2 \sigma^{2}\right)}
$$

Here, $\sigma$ is called Gaussian noise level of standard deviation.

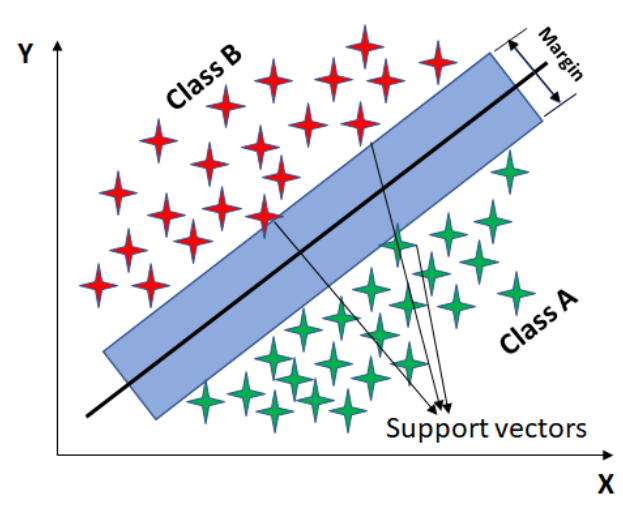

Fig. 5. Support vector representation.

Here, $X$ and $X_{i}$ are the two vectors in space. The parameter $\gamma$ represents perfect fitting of the used data set.

\section{Decision Tree}

Decision tree is another machine learning technique to solve classification as well as regression problem. It is a simple recursive structure for representing a sequential classification process in which a case, described by set of attributes, is assigned to one of disjoint set of classes [22]. Decision tree consists of root node, decision node and leaf (terminal node). Based on these parameters it divides the dataset into multiple classes as shown in Fig. 6.

In this study, a quantitative measure "Information gain" has been incorporated to split decision node into sub-nodes as shown in (9).

The information gain, Gain $(\mathrm{X}, \mathrm{A})$ of an attribute A relative to a data-set $\mathrm{X}$, is defined as [22]:

$$
\begin{array}{r}
\operatorname{Gain}(X, A)=\operatorname{Entropy}(X) \\
-\sum_{v \in \operatorname{Valuses}(A)} \frac{\left|S_{v}\right|}{|S|} \operatorname{Entropy}\left(S_{v}\right)
\end{array}
$$

Here, values $(A)$ is set of all possible values of $A$ and $S_{v}$ is the subset of $X$.

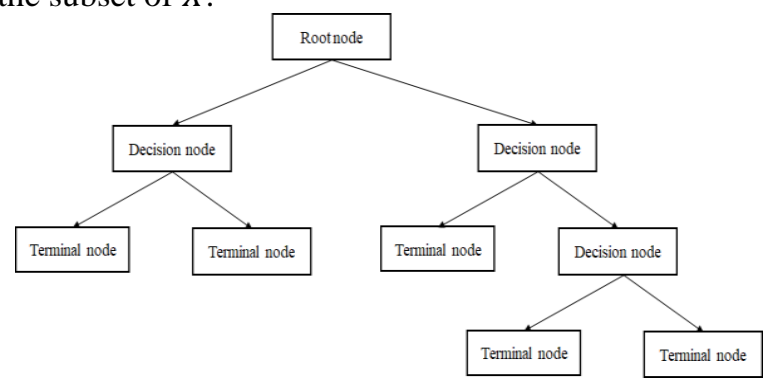

Fig. 6. Decision tree model structure.

The entropy term in the above equation has been calculated as in (10) [22]:

$$
\operatorname{Entropy}(X)=-\sum_{i=1}^{m} p_{i} \log _{2} p_{i}
$$

Here, $X$ is the data-set, $p_{i}$ is the proportion of $X$ which belongs to classi.

Blue Eyes Intelligence Engineering 


\section{Random Forest}

Random forest, another supervised regression technique, is an extension of above decision tree algorithm explained previously. It divides the whole data-set into number of subsets which are used to form the multiple regression trees [23] as shown in Fig. 7. Further it combines all the modelled trees and forms the best model. Random forest algorithm uses bootstrap sampling for sampling of input data [23].

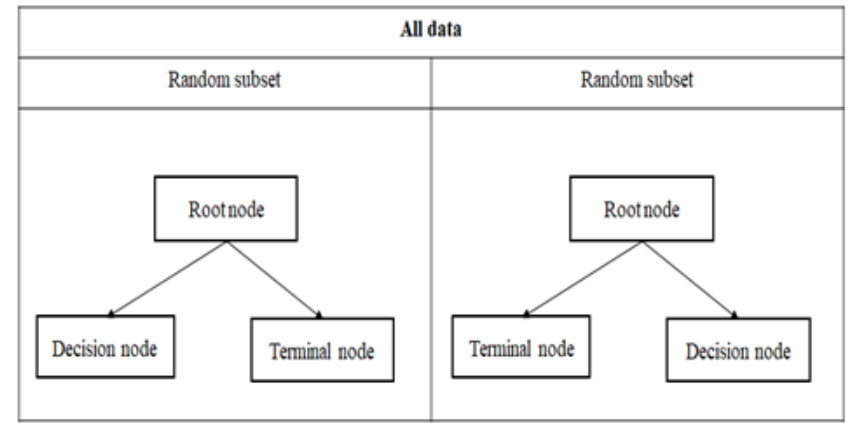

Fig. 7. Random forest multiple trees structure.

\section{E. Extreme Gradient Boosting (XGBoost)}

It is another tree based supervised machine learning algorithm. It is an efficient and scalable implementation of gradient boosting algorithm [24]. To formulate the model, an objective function $F_{o b j}$ is defined in (11) which comprises of an error term $(L)$ and regularization term $(\Omega)$ [25].

Here,

$$
F_{o b j}(\varnothing)=L(\varnothing)+\Omega(\varnothing)
$$

$$
\begin{aligned}
& L(\varnothing)=l\left(y, y_{p}\right)+\alpha T \\
& \Omega(\varnothing)=\frac{1}{2}\left(\gamma\|w\|^{2}\right)
\end{aligned}
$$

The terms $l, y, y_{p}, \alpha, T, \gamma$ and $w$ in the above (12) and (13) represents loss function, target value (output), predicted value, learning rate, number of leaf in the tree, regularization parameter and weight of the leaf respectively [23]. The loss function expressed in above (12) is mathematically defined in the forms of mean square error as shown in (14).

$$
l\left(y, y_{p}\right)=\left(y-y_{p}\right)^{2}
$$

The objective function $F_{o b j}$ is minimized considering optimization of its weightage parameters.

\section{FINAL MODEL SELECTION AND PERFOR- MANCE BOOSTING}

All the models have been implemented through cross validation technique [26]. Whole data (feature variables and target variable) was bifurcated into training data and test data for cross-validation of regression models as shown in Fig. 8. At first stage, the models have been trained on training data-set and then it is fitted to the test data set. In this work, $80 \%$ of the data has been chosen for training and $20 \%$ of the data has been used for testing.

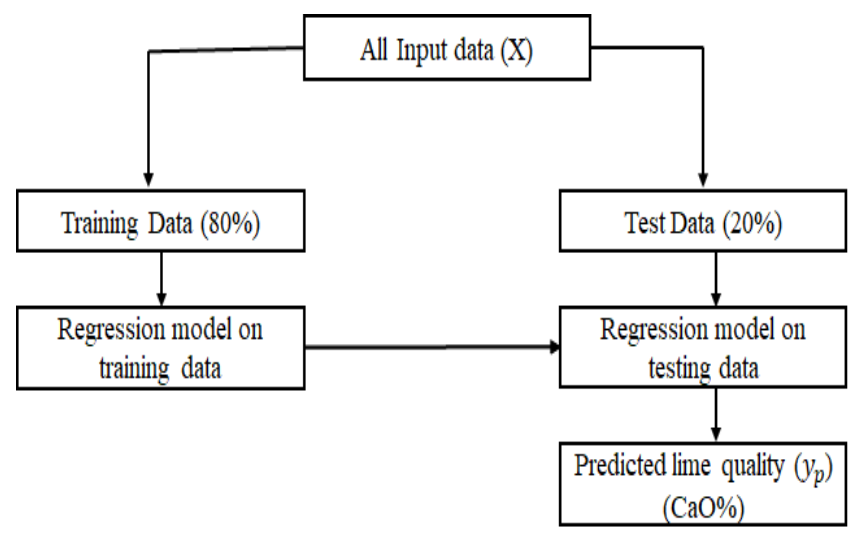

Fig. 8. Cross-validation of the model.

\section{A. Final Model Selection}

Considering the goal of this study, all model's performances have been evaluated on the basis of root mean square error (RMSE). The two performance evaluation metrics are given by the below mathematical (15) and (16). The final model has been selected which has the least RMSE [29].

$$
R M S E=\sqrt{\frac{\sum_{i=1}^{n}\left(X_{o, i}-X_{m, i}\right)^{2}}{n}}
$$

There is another evaluation parameter called mean absolute error (MAE) as shown in (18).

$$
M A E=\frac{\sum_{i=1}^{n}\left(X_{o, i}-X_{m, i}\right)}{n}
$$

Where $X_{o}$ represents observed values and $X_{m}$ is modelled values at $\mathrm{i}^{\text {th }}$ time.

\section{B. Performance Boosting}

Below are the two measures which have been incorporated to improve the models' performance:

\section{(a) Hyper-Parameter Tuning}

Hyper-parameters incorporated in the all machine learning kernels play a crucial role in transforming the data from linear to non-linear space. The different hyper-parameters used in the model have been tuned in iterations using the grid-search algorithm [27, 28]. The grid-search algorithm optimizes the models' hyper-parameters using the above cross-validation technique as shown in Fig. 9.

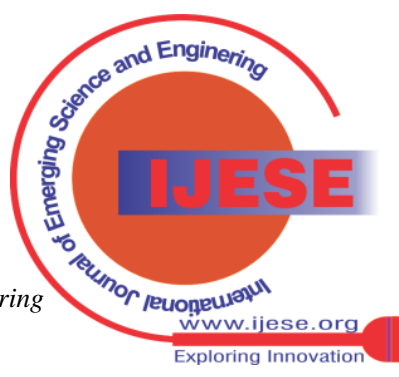




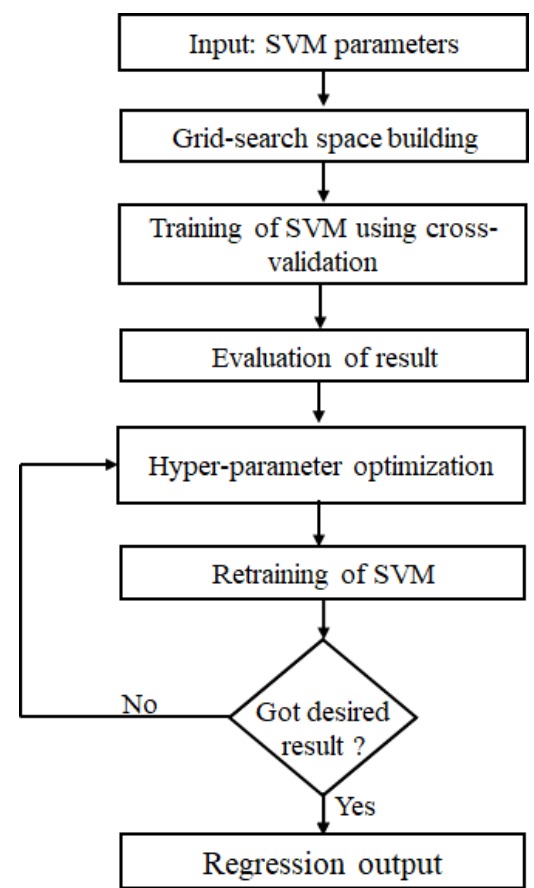

Fig. 9. Grid-search algorithm in SVM model.

In this study, hyper-parameters of all the above models have been optimized. One of the models, i.e. SVM model, gave the best accuracy in output with optimized hyperparameters with $\mathrm{C}$ (regularization parameter), $\gamma$ (gamma) and $\varepsilon$ (loss function) having values $0.005,0.5$ and 0.0001 respectively.

\section{(b) Self-learning Algorithm}

In this study, a self-learning algorithm has been incorporated based on exponential time-series technique at the stage of implementation of the SVM model in the real-time. This integration of self-learning approach in the final model corrects the real-time error and improves the hourly predictions of lime quality ( $\mathrm{CaO} \%)$ as expressed in (18). A correction factor $\left(C_{f}\right)$ based on exponential time-series technique has been calculated as shown in (17).

$$
\begin{gathered}
C_{f}=w_{1}\left(C_{a}-C_{p}\right)+w_{2}\left(C_{a}-C_{p}\right) \ldots \ldots \ldots \\
+w_{n}\left(C_{a}-C_{p}\right)
\end{gathered}
$$

Here, $\quad C_{a}=$ Actual $\mathrm{CaO} \%$

$C_{p}=$ Predicted $\mathrm{CaO} \%$

$w_{n}$ is the correction coefficient where $W_{1}>W_{2}$

$>\ldots \ldots .>W_{n}$

Hence final prediction equation is given as:

$$
C_{p_{t}}^{\prime}=C_{p_{t}}+C_{f}
$$

Where $C_{p_{t}}^{\prime}$ and $C_{p_{t}}$ is predicted $\mathrm{CaO} \%$ and corrected prediction at time trespectively.

\section{CONTROL MODEL DEVELOPMENT}

Based on the $\mathrm{CaO} \%$ prediction of above predictive model with least RSME, a control model has been developed. The golden batch of input data that resulted into acceptable quality of lime $(\mathrm{CaO} \%)$ has been used to calculate lower control limit (LCL) and upper control limit (UCL) for the variation of process parameters. It checks for any abnormal variation in process parameter values based LCL and UCL. Finally, it gives the action points as prescription to tune the process parameters' $s$ value for controlling the future lime quality $(\mathrm{CaO} \%) 12$ hours before the final production of lime. Therefore, user gets enough time to control the lime quality during the production and eventually 24 hours' time lag is eliminated. Fig. 10 shows the control model working to tune the set points on hourly basis.

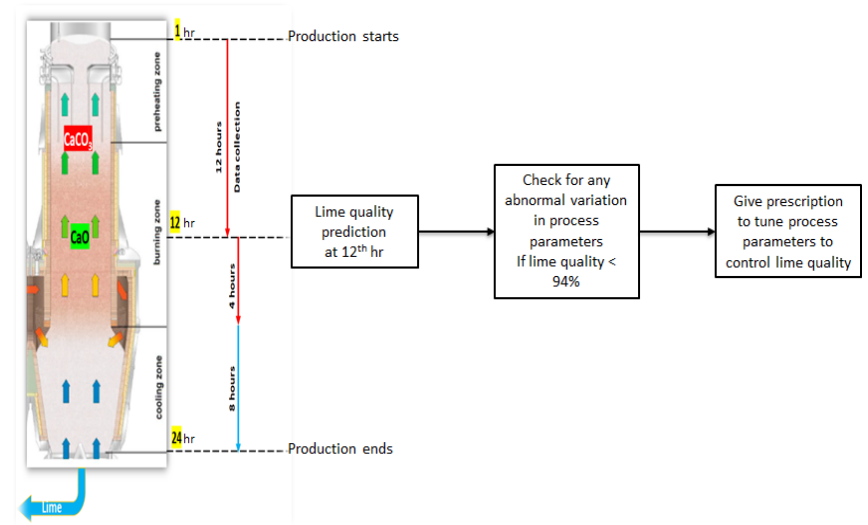

Fig. 10. Working of control model.

\section{RESULTS AND VALIDATION}

This section includes the all results obtained and their visualization from the best model, i.e. SVM. The results have been validated with experimental data of the corresponding kiln. At first, the best model has been chosen using performance metric and then $\mathrm{CaO} \%$ prediction results have been presented and validated for that model. Moreover, validation of prescriptive model result with experimental data has also been included followed by prediction.

\section{A. Model Performance Evaluation Metric}

The different metrics listed in Table II are used for measuring the model's performance through comparison.

Table-II: Models metrics.

\begin{tabular}{|c|c|c|}
\hline Model names & $\begin{array}{c}\text { Mean absolute } \\
\text { error (MAE) }\end{array}$ & $\begin{array}{c}\text { Root mean square } \\
\text { error (RMSE) }\end{array}$ \\
\hline $\begin{array}{c}\text { Multivariate } \\
\text { linear regression }\end{array}$ & 0.96 & 1.26 \\
\hline $\begin{array}{c}\text { Support vector } \\
\text { machine }\end{array}$ & 0.92 & 1.23 \\
\hline Decision tree & 0.92 & 1.26 \\
\hline Radom forest & 1.02 & 1.31 \\
\hline $\begin{array}{c}\text { Extreme gradient } \\
\text { boosting }\end{array}$ & 1.10 & 1.46 \\
\hline
\end{tabular}

From the above values of RMSE, it is clear that support vector machine model (SVM) has the least value of error among all. The value RMSE of magnitude 1.23 is found acceptable as per user demand. Eventually, SVM model has been chosen as the best model for this study.

Published By:

Blue Eyes Intelligence Engineering

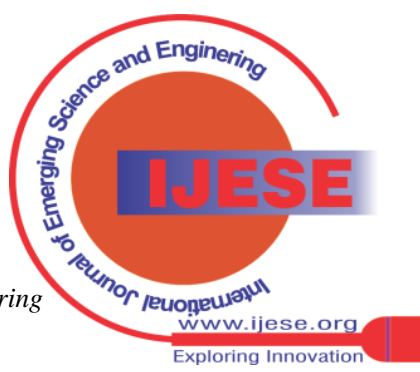




\section{B. Feature Importance}

Below Fig. 11 shows the importance of the features (input parameters) in predicting the final output $(\mathrm{CaO} \%)$ based on standardized coefficients of all process parameters. Feature importance helps in knowing the importance of process parameters in predicting the lime quality.

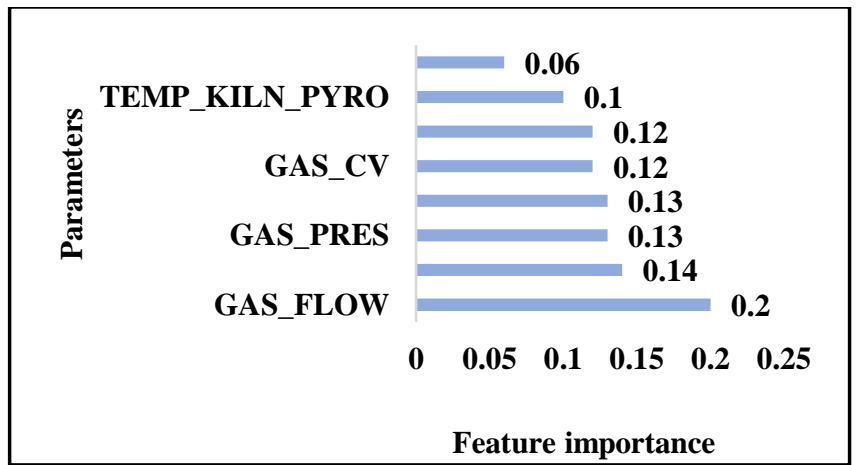

Fig. 11. Feature importance of input parameters.

\section{Visualization of Actual $\mathrm{CaO} \%$ and Predicted $\mathrm{CaO} \%$}

Below Fig. 12 shows the variation of actual $\mathrm{CaO} \%$ and predicted $\mathrm{CaO} \%$ during the prediction cycle. It is observed that model has captured enough variation of actual $\mathrm{CaO} \%$ in predicting the future value of $\mathrm{CaO} \%$.

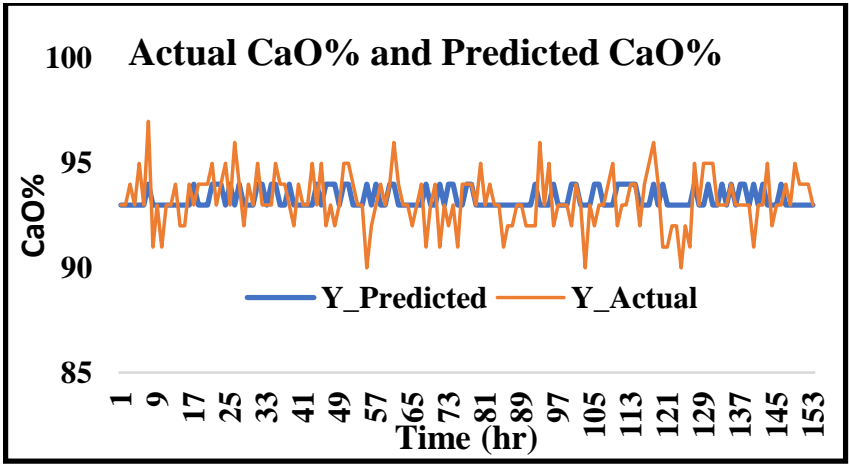

Fig. 12. Line plot of actual $\mathrm{CaO} \%$ and predicted $\mathrm{CaO} \%$.

\section{Variation within Residuals}

Variation of residuals (deviation of predicted $\mathrm{CaO} \%$ from actual $\mathrm{CaO} \%$ ) has been shown in the below Fig. 13 as box plot. Since the median value of the residual is near zero, it is concluded that $75 \%$ of the residual fall between the rage of -1 and 1 .

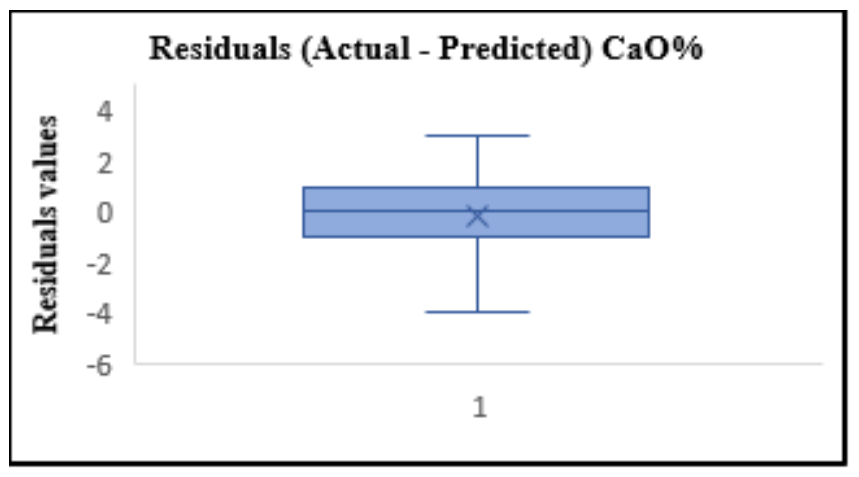

Fig. 13. Box plot of residuals.

\section{E. Model Validation Test}

A validation test has also been performed based on qualitative and quantitative parameters respectively. Model has been validated with real time plant data (experimental data) of $\mathrm{CaO} \%$.

\section{(a) Validation with real-time experimental data}

In this study, the predictive model performance has also been validated with the real-time experimental data (Lab data) of $\mathrm{CaO} \%$. For this purpose, the model was deployed in the real-time production and a quantitative study has been performed to test the validity of prediction of $\mathrm{CaO} \%$ with experimental result (lab data). Moreover, the same validation study has also been performed for prescriptive model.

\section{(a.1) Predictive Model Validation In Real-Time}

Validation of predictive model with real-time experimental data (Lab data) has been presented in Fig. 14. It is observed from the plot that model has very close prediction of $\mathrm{CaO} \%$ with actual experimental data. Quantitatively, the model has given the accuracy of $90 \%$ in error range of -1 to 1 with integration of self-learning approach.

\section{(a.1.1) Validation of predicted $\mathrm{CaO} \%$ with actual $\mathrm{CaO} \%$}

Figure 14 shows the comparison graph for actual $\mathrm{CaO} \%$ (plant data) and predicted $\mathrm{CaO} \%$ when prediction cycle was run hourly in real-time. Fig. 15 shows the frequency of error came between the range of -1 and 1 while testing the model on 187 data points. It is clear that more than $90 \%$ of the error fell into the band of -1 and 1 .

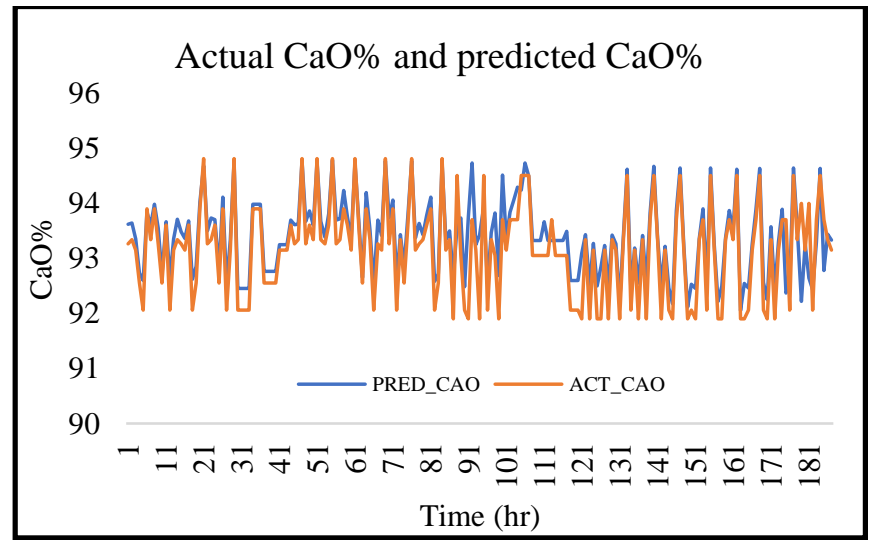

Fig. 14.Variation of actual and predicted $\mathrm{CaO} \%$.

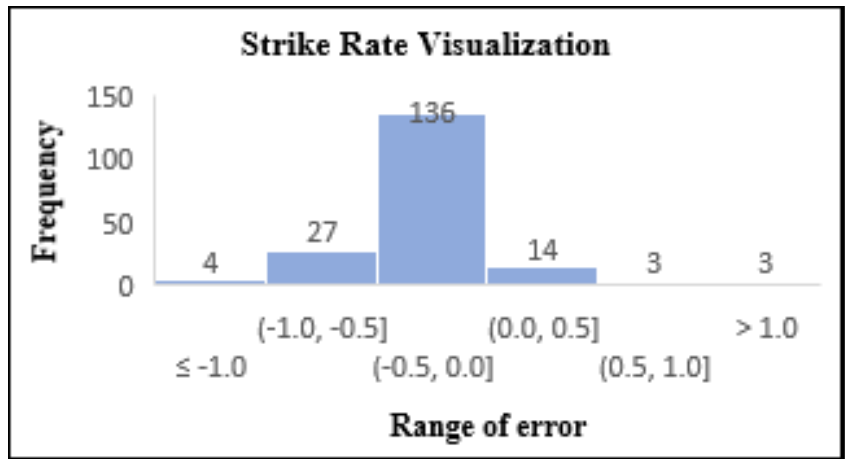

Fig. 15. Strike-rate visualization of predictive model.

Published By:

Blue Eyes Intelligence Engineering and Sciences Publication

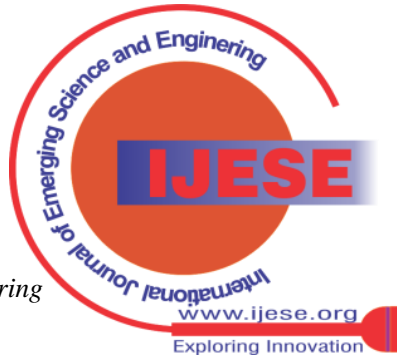




\section{(a.1.2) Variation of residual during prediction}

Below Fig. 16 shows the variation of residual error (Deviation of predicted $\mathrm{CaO} \%$ from actual $\mathrm{CaO} \%$ ) as a box plot. It is clear from the plot that the variation is very narrow with residual values varying from -1 to 0.5 . However, some outlier values of residual errors have also been observed. An average error of -0.23 has been observed between predicted and actual value of lime quality (available $\mathrm{CaO} \%$ in quicklime).

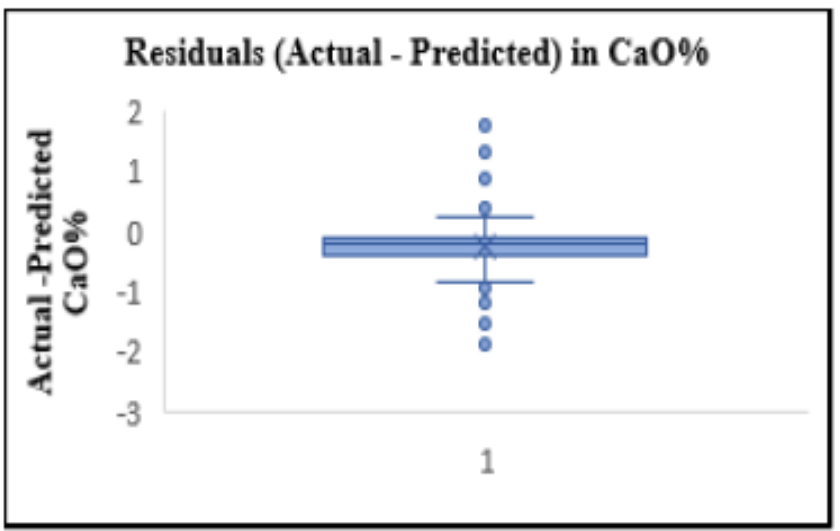

Fig. 16. Variation of residuals during prediction.

\section{(a.2) Control model validation in real-time}

The above validation test has also been performed for the control model. The validation contains comparison of variation in $\mathrm{CaO} \%$ prescribed by the model with plant data (Lab data) in real-time.

\section{(a.2.1) Validation of prescribed $\mathrm{CaO} \%$ with actual $\mathrm{CaO} \%$}

Below Fig. 17 shows the comparative study of prescribed $\mathrm{CaO} \%$ (lime quality predicted by control model) with the values obtained from real-time experimental results. It can be clearly observed from the plot that $\mathrm{CaO} \%$ values in both cases are very close. Quantitative measurement in Fig. 18 shows that the model has 90\% accuracy to prescribe $\mathrm{CaO} \%$ same as experimental value with integration of self-learning approach.

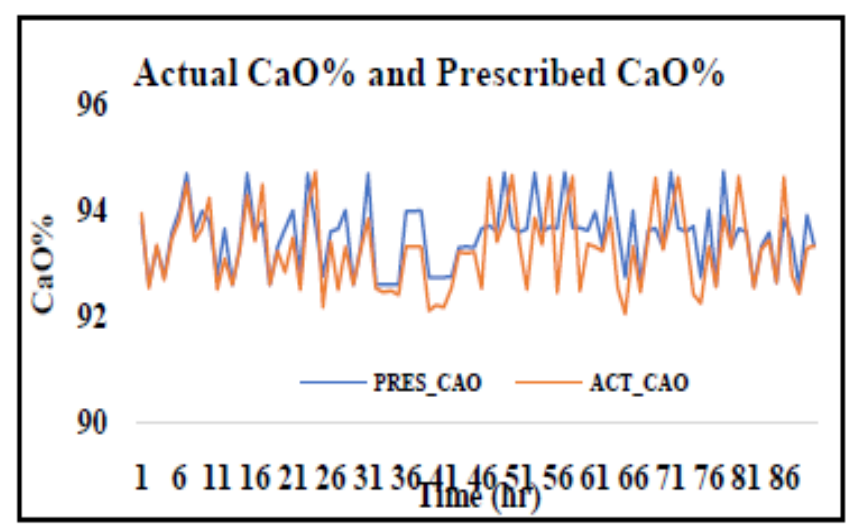

Fig. 17. Variation of actual $\mathrm{CaO} \%$ and prescribed $\mathrm{CaO} \%$.

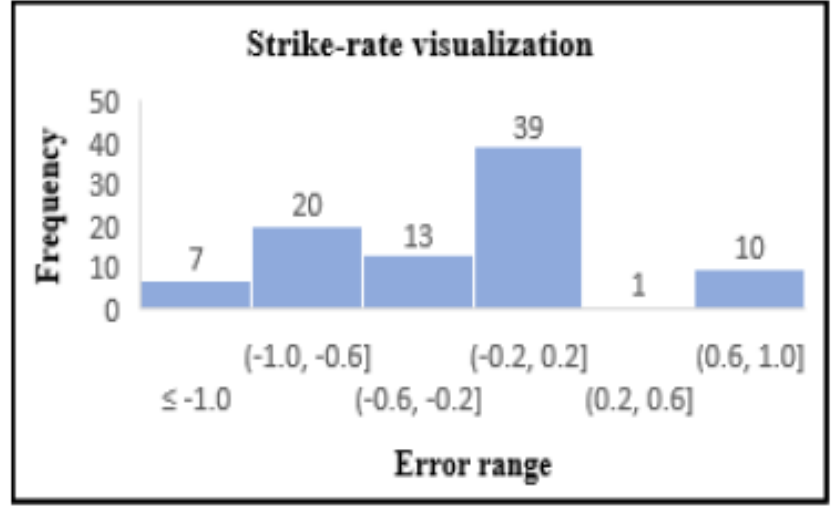

Fig. 18. Strike-rate visualization of control model.

\section{(a.2.2) Variation of residuals during prescription}

Variation of residual errors (Deviation of prescribed $\mathrm{CaO} \%$ from actual $\mathrm{CaO} \%$ ) has been plotted in Fig. 19. The box plot shows that residual error's values fall within a narrow band of -1 to 1 which is entirely good as far as the scope of this study is concerned. An average error of -0.24 has been observed between predicted and actual value of lime quality (available $\mathrm{CaO} \%$ in quicklime).

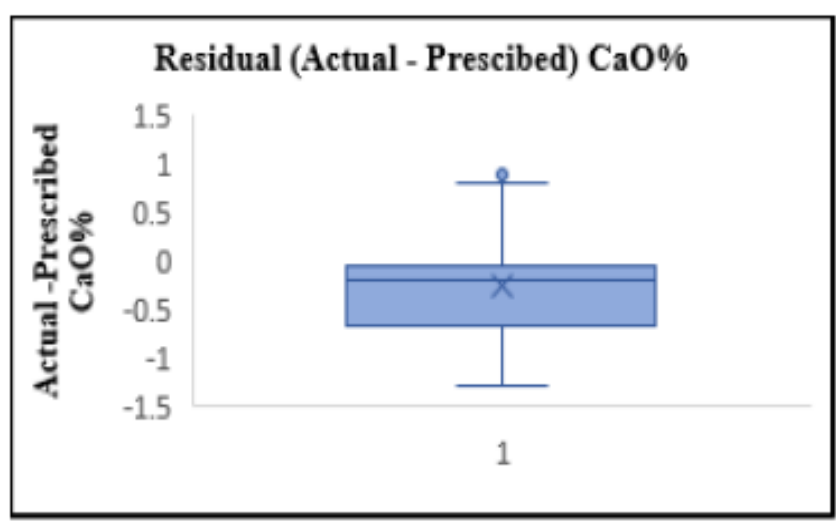

Fig. 19. Variation of residuals during prescription.

\section{DEPLOYMENT OF MODEL}

A human machine interface (HMI) has been developed and deployed inside lime plant at Tata Steel for the use of control model in real scenario as shown in Fig. 20. There are total 9 Merz-kiln (namely MK1 to MK9) in the lime plant of Tata Steel to produce lime. The interface contains the prescription given by the model with time to control the future lime quality. For each prediction of lime quality there exists a prescription when quality goes below $94 \%$ level. As result, operator (user) takes action based on these prescriptions so that future lime quality can be improved.

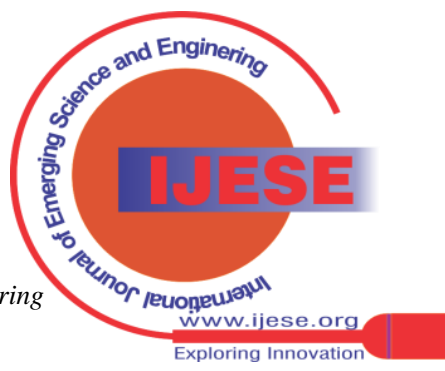




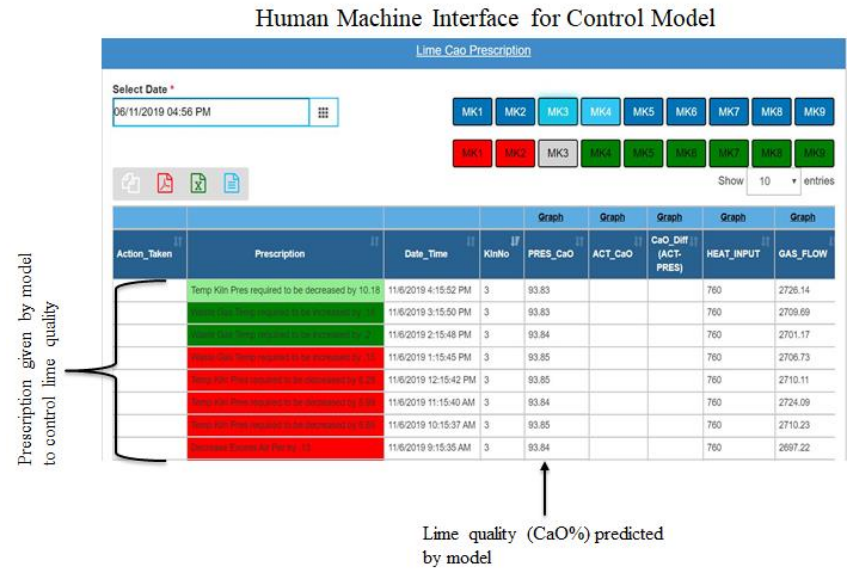

Fig. 20. Human machine interface developed for control model.

\section{CONCLUSIONS}

(1) Among all the machine-learning models such as multivariate linear regression, support vector machine, random forest, decision tree and XGboost; the final predictive model is developed by incorporating support vector machine model with the best accuracy value of 1.23 in terms of RMSE. The accuracy obtained falls within user defined limit.

(2) The predictive model predicts the $\mathrm{CaO} \%$ in quicklime on hourly basis at the end of the lime production cycle in Merz-kiln.

(3) Based on the predictive model, a control model predicts the $\mathrm{CaO} \%$ in quicklime 12 hours in advance of the production cycle. Further it prescribes appropriate actions to the user for controlling the level of $\mathrm{CaO} \%$ (lime quality) on hourly basis.

(4) Quantitative validation (On experimental/Lab data/Plant data) of both the models (predictive and control) resulted in average errors of -0.24 and -0.23 in predicted lime quality with actual lime quality.

(5) Model accuracy has further improved from $85 \%$ in \pm 2 to $90 \%$ in \pm 1 with the integration of the self-learning approach.

(6) Control model with a human-machine-interface facilitates the user to take action on process parameter to control lime quality. This eliminates the 24 hrs of time lag in decision making.

\section{ACKNOWLEGEMENT}

The authors are highly grateful to the International Journal of Emerging Science and Engineering for supporting this research work.

\section{REFERENCES}

1. Manocha, Sanjeev, and François Ponchon. "Management of Lime in Steel." Metals, vol. 8, no. 9, 2018, p. 686., doi:10.3390/met8090686.

2. Obst, K.-H.; Stradtmann, J. The influence of lime and synthetic lime products on steel production. J. S. Afr.Inst. Min. Metall. 1972, 72 , 158-164.

3. Schrama, Frank Nicolaas Hermanus, et al. "Sulphur Removal in Ironmaking and Oxygen Steelmaking." Ironmaking \& Steelmaking, vol. 44, no. 5, 2017, pp. 333-343., doi:10.1080/03019233.2017.1303914.

4. Damien, et al. "The Significant Impact of Limestone Property on Sintering of Marra Mamba Iron Ore Blends."2016.

5. Eric L Crump. "Lime Production: Industry Profile." U.S. Environmental Protection Agency. Project Number - 7647-001-020, 2000.

Retrieval Number: 100.1/ijese.B2502057221

DOI: 10.35940/ijese.B2502.057221

Journal Website: www.ijese.org
6. Maerz. "General Information and Operation". Tata Steel Limited, Kiln8\&9, AK651_971.01, 2010.

7. S. W. Hagemoen et al. "An Expert System Operation for Lime Kiln Operation." Andritz Automation.

8. K.-D. Thoben et al. "Industrie 4.0 and Smart manufacturing - A Review of Research Issues and Application Example."Journal of Automation Technology, 2016.

9. B. Bajic et al. "Machine Learning Techniques for Smart Manufacturing: Application and Challenges in Industry 4.0." 2018.

10. Thorsten W. et al. "Machine Learning in manufacturing: Advantage, Challenges and Application." 2016.

11. S. Santosh, A. K. Shukla. "Data Base Modelling Approach to Iron and Steel Making Process."

12. Vinoo, D. S., Mazumdar, D., \& Gupta, S. S. "Optimisation and prediction model of hot metal desulphurisation reagent consumption." Ironmaking \& Steelmaking, 2007, 34(6), pp. 471-476. doi:10.1179/174328107x165717

13. J. Wang et al. "Deep Learning for Smart Manufacturing: Methods and Application." Journal of Manufacturing System, 2018.

14. N. F. Wajiralilah et al. "A Review on Convolution Neural Network on Bear Fault Diagnosys." MATEC Web of Conferences, 2019.

15. P. Wang et al. "A Deep Learning Based Approach to Material Removal Rate Prediction in Policing." Manufacturing Technology, 2017.

16. S. J. Shin et al. "Predictive Analytics Model for Power Consumption in Manufacturing." Engineering, 2014.

17. K. Rajesh, A. K. Ray. "Artificial Neural Network for Solving Paper Industry Problem: A Review." Journal of Scientific and Industrial Research, vol. 65, pp. 565-573, 2006.

18. T. Zhongda et al. "SVM Predictive Control for Calcination Zone Temperature in Lime Rotary Kiln with Improved PSO Algorithm." Vol 40, 2017.

19. N. Sethi, D. K. Garg. "Exploiting Data Mining Technique for Rainfall Prediction." International Journal of Computer Science and Information Technology, Vol 5(3), 2014.

20. Y. Radhika, M. Shashi. "Atmospheric Temperature Prediction using Support Vector Machine.” International Journal of Computer Theory and Engineering, Vol 1, 2009.

21. O. Kisi, M. Cimen. "Evapotranspiration Modelling Using Support Vector Machines.” Hydrological Sciences Journal, 2010, pp. 918928, doi: 10.1623/hysj.54.5.918.

22. J. Mesaric, D. Sebalj. "Decision Tree for Predicting the Academic Success of Students.” Croatian Operational Research Review, 2016.

23. M. G. Roberts et al. "Automatic Location of Vertebrae on DXA Image Using Random Forest Regression.” MICCAI, Part III, 2012.

24. T. Chen, T. He. "xgboost: Extreme Gradient Boosting." 2019.

25. Zhang, X., Deng, T., \& Jia, G. "Nuclear spin-spin coupling constants prediction based on XGBoost and LightGBM Algorithms." Molecular Physics, 2019, pp. 1-10, doi:10.1080/00268976.2019.1696478

26. I. Tsamardinos, A. Rakhshani, and V. Lagani, "Performanceestimation properties of cross-validation based protocols with simultaneous hyper-parameter optimization," International Journal on Artificial Intelligence Tools, 2015

27. I. Syarif et al. "SVM Parameter Optimization using Grid Search and Genetic Algorithm to Improve Classification Problem." Vol 14, 2016, doi: 10.12928.

28. J. Bergstra, Y. Bengio, "Random Search for Hyper-Parameter Optimization.” Journal of Machine Learning Research, 2012.

29. A. Sanz-Garcia et al. "Overall Models Based on Ensemble Methods for Predicting Continuous Annealing Furnace Temperature Setting." Ironmaking \& Steelmaking, 2013, pp. 51-60, doi 10.1179/1743281213Y.0000000104

\section{AUTHORS PROFILE}

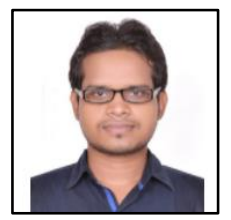

Vipul Kumar Tiwari, Technologist, Automation Division, Tata Steel, Jamshedpur, 831001, India. Email: vipul.tiwari1@tatasteel.com Mob: 9262691920

Published By:

Blue Eyes Intelligence Engineering 9 and Sciences Publication (C) Copyright: All rights reserved.

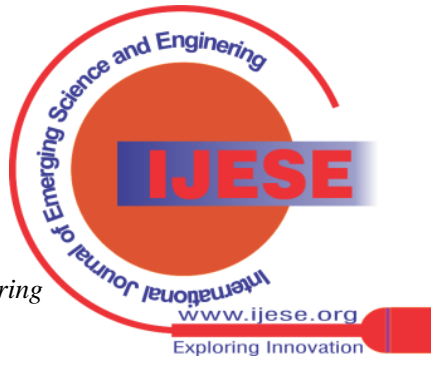




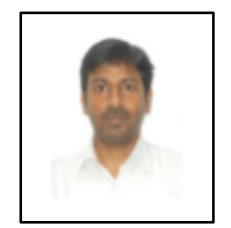

Abhishek Choudhary, Sr. Manager, Lime plant, Tata Steel, Jamshedpur, 831001, India E-mail: abhishek.c@tatasteel.com

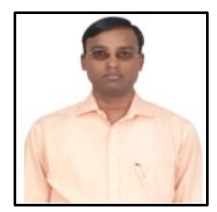

Umesh Kr. Singh, Principal Technologist, Automation Division, Tata Steel, Jamshedpur, 831001, India. E-mail: umesh.singh1@tatasteel.com

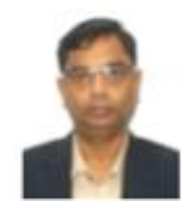

Anil Kumar Kothari, Chief (SM\&C), Automation Division, Tata Steel, Jamshedpur, 831001, India. E-mail: anil.kothari@tatasteel.com

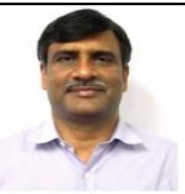

Manish Kr. Singh, Chief (One IT), Automation Division, Tata Steel, Jamshedpur, 831001, India. E-mail: manishk.singh@tatasteel.com

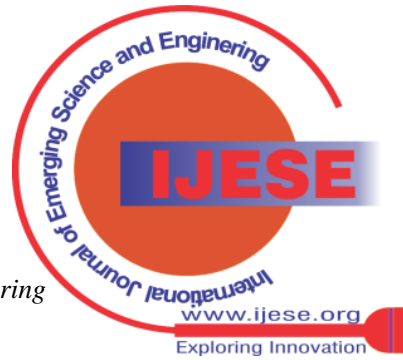

